\title{
Mice exclusively expressing the short isoform of Smad2 develop normally and are viable and fertile
}

\author{
N. Ray Dunn, ${ }^{1}$ Chad H. Koonce, ${ }^{2}$ Dorian C. Anderson, Ayesha Islam, ${ }^{2}$ Elizabeth K. Bikoff, ${ }^{2}$ and \\ Elizabeth J. Robertson ${ }^{2,3}$
}

Department of Molecular and Cellular Biology, Harvard University, Cambridge, Massachusetts 02138, USA

\begin{abstract}
Smad2 and Smad3 are closely related effectors of TGFß/Nodal/Activin-related signaling. Smad3 mutant mice develop normally, whereas Smad2 plays an essential role in patterning the embryonic axis and specification of definitive endoderm. Alternative splicing of Smad2 exon 3 gives rise to two distinct protein isoforms. The short Smad2(Aexon3) isoform, unlike full-length Smad2, Smad2(FL), retains DNA-binding activity. Here, we show that $\operatorname{Smad2}(F L)$ and $S m a d 2(\Delta e x o n 3)$ are coexpressed throughout mouse development. Directed

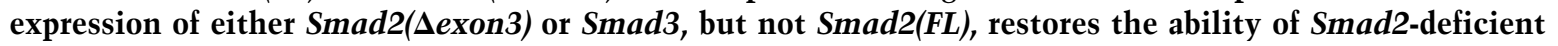
embryonic stem (ES) cells to contribute descendants to the definitive endoderm in wild-type host embryos.

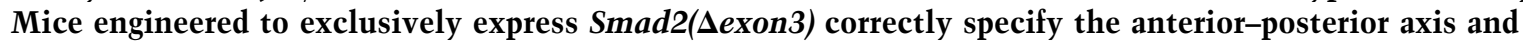
definitive endoderm, and are viable and fertile. Moreover, introducing a human Smad3 cDNA into the mouse Smad2 locus similarly rescues anterior-posterior patterning and definitive endoderm formation and results in adult viability. Collectively, these results demonstrate that the short Smad2(Aexon3) isoform or Smad3, but not full-length Smad2, activates all essential target genes downstream of TGFß-related ligands, including those regulated by Nodal.
\end{abstract}

[Keywords: Smad2; Smad3; alternative splicing; chimeras; definitive endoderm; redundancy]

Received July 22, 2004; revised version accepted November 2, 2004.

Transforming growth factor $\beta$ (TGF $\beta$ )-related ligands comprise one of the largest groups of cytokines encoded in the vertebrate genome (Venter et al. 2001). They govern fundamental cell fate decisions in the embryo and are intimately involved in the maintenance of tissue homeostasis throughout postnatal life (for review, see Whitman 1998; Massagué et al. 2000). At the cell surface, the concentration of available ligand is interpreted by a receptor complex containing type I and type II serine-threonine kinases. Ligand-dependent activation of the type I receptor kinase triggers phosphorylation of a family of intracellular effector proteins termed Smads. The activated receptor-regulated Smads (R-Smads) then oligomerize with a structurally related collaborator, Smad4, and this heteromeric complex moves to the nucleus to regulate the transcription of target genes.

Present addresses: ${ }^{1}$ ES Cell International, 11 Biopolis Way, \#05-06 Helios, Singapore $138667 ;{ }^{2}$ Wellcome Trust Centre for Human Genetics, University of Oxford, Roosevelt Drive, Oxford OX3 7BN, United Kingdom.

${ }^{3}$ Corresponding author.

EMAIL: Elizabeth.Robertson@well.ox.ac.uk; FAX 44-1865-287776. Article and publication are at http://www.genesdev.org/cgi/doi/10.1101/ gad. 1243205
Smad2 and Smad3 function as R-Smads downstream of prototypical TGF $\beta$ ligands, Nodal, Activin, and some growth and differentiation factors (GDF) (Wall et al. 2000; Miyazawa et al. 2002; Cheng et al. 2003; Shi and Massagué 2003). These two molecules share $92 \%$ amino acid identity overall and display even greater similarity in the C-terminal $\mathrm{MH} 2$ protein-protein interaction domain (Fig. 1B). Flies and worms, unlike vertebrates, have only one Smad2/3-related gene, dSmad2/Smox and sma2 , respectively. It appears that gene duplication events within the chordate phyla gave rise to Smad2 and Smad3 (Newfeld et al. 1999; Dehal et al. 2002). In mice and humans, these loci show striking similarities in their linkage and genomic organization, with a near one-toone correspondence in exon size (Fig. 1A). However, the prevailing model holds that Smad2 and Smad3 have significantly diverged and are nonredundant.

Recent work demonstrates that Smad2 and Smad3 exist in distinct oligomeric complexes at steady state. Thus, Smad2 is found mostly as a monomer within the cytoplasm, while Smad3 constitutively forms higher-order complexes (Jayaraman and Massagué 2000). After ligand-dependent phosphorylation, Smad2 and Smad3 are released from cytoplasmic retention proteins such as SARA and assemble into multimeric complexes with Smad4, and this activated complex is next imported into 
A
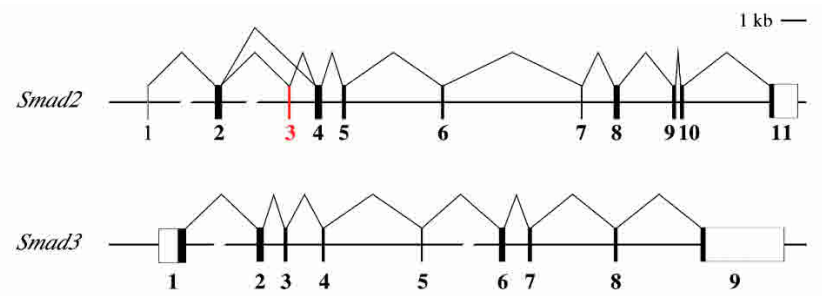

B

$$
\operatorname{Smad} 2(\mathrm{FL})
$$

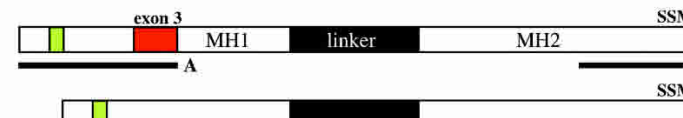

$\operatorname{Smad} 2(\Delta$ exon 3$)$

Smad3

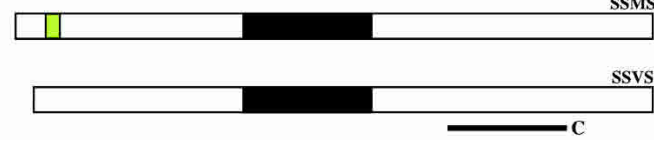

467 aa 437 aа 425 aa
Figure 1. Smad2 and Smad3 structural comparisons. (A) Mouse Smad2 and Smad3 genomic organization. The alternatively spliced Smad2 exon 3 and the corresponding 30-amino acid insert it encodes are shown in red. Noncoding exons are depicted as open rectangles. Smad2 exons 4-11 and Smad3 exons 2-9 are nearly identical in size. $(B) \mathrm{Smad} 2$ and Smad3 protein alignments showing the highly conserved $\mathrm{N}$-terminal and C-terminal Mad Homology domains 1 (MH1) and $2(\mathrm{MH} 2)$, respectively, and the intervening proline-rich linker region. The Smad2 MH1 domain also contains an $\mathrm{N}$-terminal glycine-rich 10 -amino acid insert (yellow) that is not present in Smad3. Smad2 and Smad3 possess distinct C-terminal SS(V/M)S phosphorylation motifs. The sequences corresponding to those protected by RPA probes are indicated as black lines. the nucleus (Tsukazaki et al. 1998; Di Guglielmo et al. 2003). Smad2 interacts directly with nucleopore components via its $\mathrm{MH} 2$ domain, whereas Smad3 uses the classical importin- $\beta$-dependent nuclear transport pathway (for review, see Reguly and Wrana 2003; Xu and Massagué 2004). Smad3 binds DNA with low affinity via the novel $\beta$-hairpin DNA-interaction motif within the MH1 domain (Shi et al. 1998). In contrast, Smad2 cannot bind DNA due to the presence of a unique 30-amino acid insert that lies just $\mathrm{N}$-terminal to the $\beta$-hairpin (Dennler et al. 1999; Yagi et al. 1999). Interestingly, the inability of Smad2 to interact with itself or other proteins at steady state or to use the importin- $\beta$ nuclear transport pathway has been attributed to the presence of this unique insert encoded by the alternatively spliced exon 3 (Fig. 1A; Jayaraman and Massagué 2000; Kurisaki et al. 2001).

Heteromeric Smad complexes associate with an array of tissue-specific transcription factors, coactivators, and corepressors (for review, see Massagué and Wotton 2000; Miyazawa et al. 2002; Liu 2003). Consistent with their different mechanisms of nuclear import and DNA binding, several distinct transcriptional partners have been identified that specifically interact with either Smad2 or Smad3. For example, Smad3 associates with HNF4 to transactivate the apolipoprotein $C$-III promoter, while Smad3-FoxO protein complexes directly regulate the p21Cip1 growth inhibitory gene to achieve TGF $\beta$-dependent cytostasis (Chou et al. 2003; Seoane et al. 2004). In addition, Smad2 acts in combination with the forkhead transcription factor FoxH1 (FAST) and Smad4 to activate the goosecoid promoter, while Smad3-containing complexes inhibit expression (Labbé et al. 1998). Taken together, these observations strongly suggest that Smad2 and Smad3 play unique roles downstream of TGF $\beta$-related growth factors.

Smad2 and Smad3 are further distinguished by their loss-of-function phenotypes. Smad3 mutant mice are viable and fertile (Zhu et al. 1998; Datto et al. 1999; Yang et al. 1999). In contrast, Smad2 mutant embryos fail to form the specialized extraembryonic signaling center known as the anterior visceral endoderm (AVE) (Waldrip et al. 1998; Heyer et al. 1999|. Consequently, these embryos lack anterior-posterior (A-P) polarity and are highly disorganized by embryonic day 8.5 (E8.5). The dramatic phenotypic difference between Smad2 and Smad3 mutant mice results from the expression of Smad2 and not Smad3 in the AVE (Tremblay et al. 2000). Recent experiments with Smad2-deficient embryonic stem (ES) cells and studies of conditional gene inactivation within the early epiblast reveal a second, focal requirement for high levels of Smad2 in the specification of definitive endoderm during gastrulation (Tremblay et al. 2000; Vincent et al. 2003). Similarly, loss of Smad3 in the context of one wild-type Smad2 allele results in a failure to specify anterior primitive streak derivatives during gastrulation (Dunn et al. 2004). Consequently, these mutant embryos develop anterior truncations that are identical to those observed in embryos with decreased levels of the Nodal ligand (Vincent et al. 2003). From this more refined genetic analysis, Smad3 emerges as an essential component of the Nodal signal transduction pathway (Liu et al. 2004). Biochemical studies also show that Smad2 and Smad3 associate with the activated Alk4 type I Nodal receptor (Lebrun et al. 1999). Furthermore, in transcriptional activation assays Smad3 can regulate the ASE autoregulatory enhancer element from the Nodal gene, previously characterized as Smad2-FoxH1 dependent (Osada et al. 2000; Saijoh et al. 2000; Dunn et al. 2004). These data therefore support an opposing model that Smad2 and Smad3 are to a large degree functionally interchangeable.

Here, we investigate potentially shared or unique functional activities of Smad2 and Smad3 in the embryo. We have previously shown that descendants of Smad2deficient ES cells are greatly compromised in their ability to colonize the definitive endoderm in chimeric mouse embryos (Tremblay et al. 2000). In reconstitution experiments, the Smad2(Dexon3) splice variant and Smad3, but not full-length Smad2, can compensate for loss of Smad2 and restore these activities. Remarkably, germline deletion of exon 3 from the Smad2 locus results in $100 \%$ viability, indicating that expression of full-length Smad2 is dispensable. Finally, replacing 
Dunn et al.

Smad2 coding sequences with Smad3 also results in a homozygous viable phenotype. These results demonstrate unequivocally that the short Smad2( $\Delta$ exon3) isoform or Smad3 activate all essential TGF $\beta$ signaling pathways.

\section{Results}

\section{Expression of Smad2 isoforms in the mouse}

Alternatively spliced Smad2 transcripts have been previously documented in various human cell lines (Takenoshita et al. 1998; Yagi et al. 1999), and in frogs both Smad2(Dexon3) and Smad2(FL) are coexpressed in unfertilized eggs and during development (Faure et al. 2000). To investigate the expression of Smad2 splice variants in mice, we used a ribonuclease protection assay (RPA) probe spanning the ATG-containing exon 2 and alternatively spliced exon 3 that distinguishes Smad2(FL) and Smad2(Aexon3) transcripts (Fig. 1B). The shorter Smad2(Aexon3) transcript is strongly expressed in ES cells and mouse embryos at all stages examined as well as in adult tissues (Figs. 2A, 4D [below]). Smad2(FL) transcript levels are consistently higher than Smad2(Dexon3), but the $F L: \Delta e x o n 3$ ratio decreases at later stages (Fig. 2A). By late gestation (E16.5) the ratio is nearly 1:1 (data not shown). In adults, $\operatorname{Smad2}(F L)$ is more abundant in spleen and thymus, while Smad2sexon3 is barely detectable in liver (Fig. 4D, below). Among the diverse tissues analyzed here, the $F L: \Delta$ exon3 ratio is never greater than 3.5:1. These RNAse protection assays were repeated several times analyzing independent RNA samples to ensure that the results were reproducible. Our findings contrast with previous RT-PCR results that estimate $F L: \Delta$ exon3 expression ratios to be 10:1 in human cell lines (Takenoshita et al. 1998; Yagi et al. 1999). Taken together, these results show that the

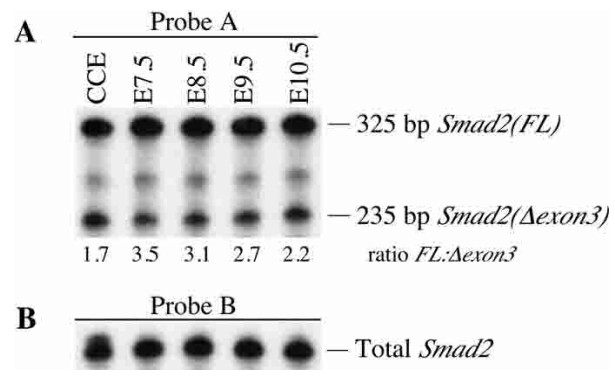

Figure 2. Smad2 splice variants are coexpressed during early mouse embryonic development. (A) Quantitative analysis of Smad2(FL) and Smad2(Aexon3) expression levels in CCE ES cell and embryonic total RNA at various stages. The size of the fragments protected by RPA probe A (Fig. 1B) is indicated. The ratio of $\operatorname{Smad2}(F L)$ to $\operatorname{Smad2(\Delta exon3)}$ expression decreases with developmental age. The expression ratios indicated by the numbers at the bottoms of the lanes were calculated by scanning the gels in a PhosphorImager and measuring the amount of radioactivity in each band to determine the precise ratios. (B) Total Smad2 transcript levels monitored with RPA probe B (Fig. 1B).
Smad2(Dexon3) splice form is dynamically regulated and represents a much higher proportion of transcripts than previously estimated by RT-PCR. One possibility is that alternative Smad2 isoforms play unique roles in the transduction of TGF $\beta$-related signals in the mouse embryo and adult.

Reconstitution of Smad2 signaling in Smad2-deficient ES cells and colonization of definitive endoderm in chimeric mouse embryos

We previously engineered the Smad2 Robm1 loss-of-function mutation in which the ATG containing exon 2 is deleted (Waldrip et al. 1998). Two independent homozygous mutant ES cell lines KT11 and KT15 were subsequently derived that constitutively express the Rosa26 lac $Z$ reporter gene (Tremblay et al. 2000). These lines efficiently colonize ectodermal and mesodermal lineages when injected into wild-type host blastocysts, but are greatly compromised in their ability to contribute to the definitive endoderm (Heyer et al. 1999; Tremblay et al. 2000).

To assess the unique or common activites of Smad2(FL) and $\operatorname{Smad} 2(\Delta$ exon3) isoforms during development, we developed a strategy to restore Smad2 signaling in these Smad2-deficient ES cell lines in gain-of-function transfection experiments. Thus, full-length cDNAs encoding N-terminally Flag-tagged human (h) Smad2(FL), Smad2(sexon3), or the closely related Smad3 proteins were inserted into a modified version of the pCAGGS vector, which directs robust expression in ES cells and early embryos and confers hygromycin resistance (Fig. 3A; Niwa et al. 1991; Yagi et al. 1999). Since the parental KT11 and KT15 ES cells lack endogenous Smad2(FL) and Smad2(sexon3) proteins (Tremblay et al. 2000; Dunn et al. 2004), drug-resistant clones were initially analyzed by flow cytometry (FACS) with an anti-Smad2/3 antibody to evaluate hSmad protein levels (Fig. 3A). Smad2(FL) and $\operatorname{Smad} 2(\Delta$ exon3) transfected clones display expression levels approximately equal to endogenous Smad2 in wild-type ES cells, while Smad3 transformants exhibit increased levels, which reflects the contribution of endogenous Smad3 (Fig. 3A). Expression of introduced human Smad proteins was also examined by Western blot analysis using the anti-Flag antibody (Fig. 3B). Finally, transfected ES cells were also treated with TGF $\beta 1$ or Activin and analyzed with an anti-phospho-Smad2 antibody to verify that hSmad proteins were efficiently phosphorylated by native receptor complexes in ES cells (data not shown). Consistent with findings by Parisi et al. (2003), we find that wild-type CCE ES cells express ActRIIA and ActRIIB type II receptors as well as the Alk2, Alk4, and Alk5 type I receptors (L. Oxburgh, N.R. Dunn, and E.J. Robertson, unpubl.). Collectively these experiments demonstrate that Flag-tagged human Smad2(FL), Smad2(Aexon3), and Smad3 proteins stably expressed in KT11/KT15 ES cell clones potentially function as effectors downstream of Nodal signals.

Transformants were next tested for their ability to 
A

A

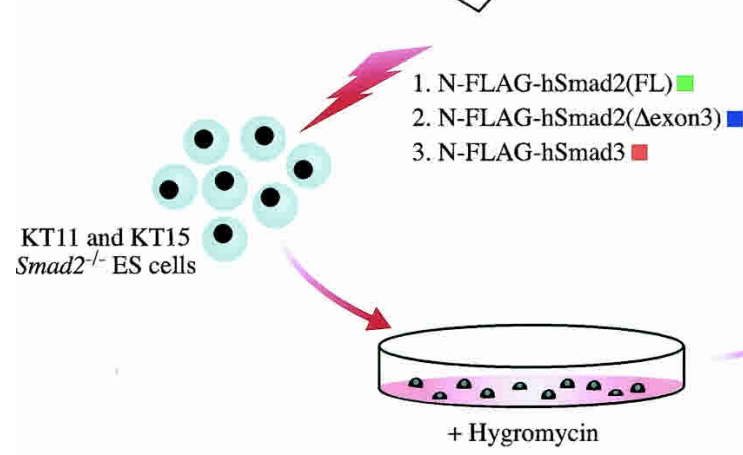

B

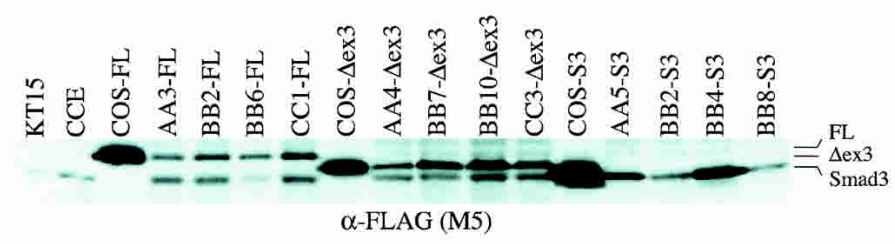

C

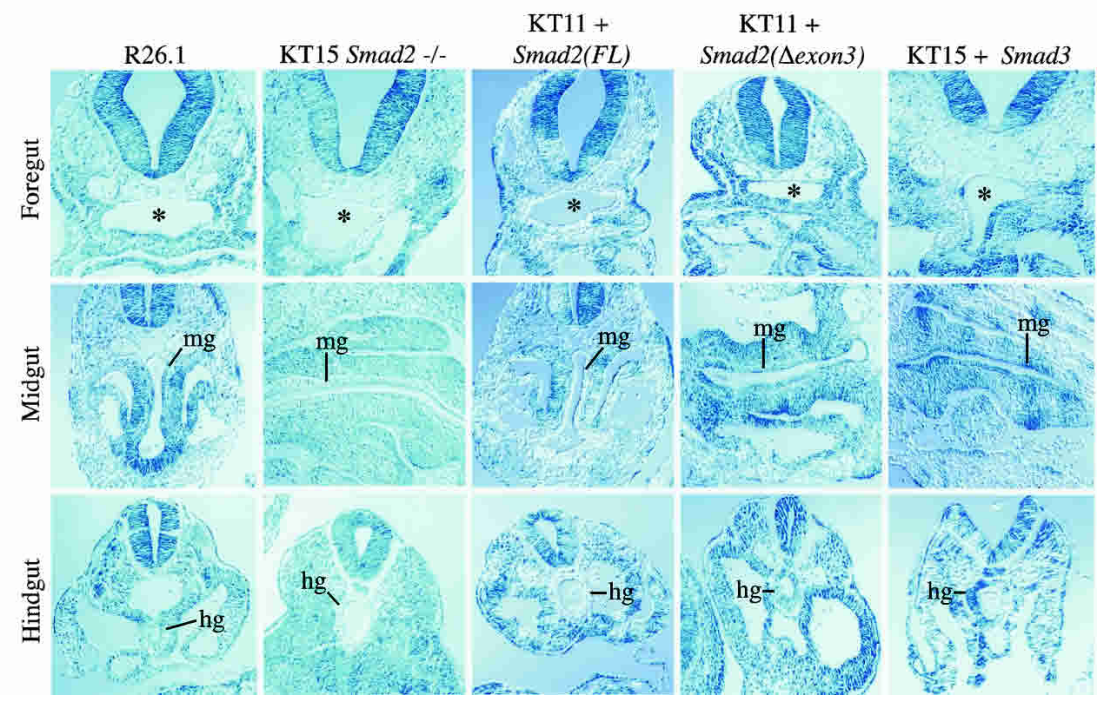

Figure 3. Reconstituted Smad2-deficient ES cells expressing $\operatorname{Smad} 2(\Delta$ exon3) or Smad3, but not Smad2(FL), contribute to the definitive endoderm in chimeric embryos. (A) Vector design and electroporation scheme. pCAGGS contains a chimeric promoter between the cytomegalovirus (CMV) immediate-early enhancer and the chicken $\beta$-actin promoter as well as the chicken $\beta$-globin intron and rabbit $\beta$-globin polyadenylation signals. cDNAs encoding N-terminally Flag-tagged human

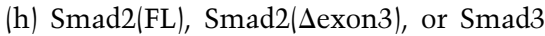
were introduced into Smad2 ${ }^{R o b m 1}$ homozygous ES cells. Hygromycin-resistant clones were initially screened by flow cytometry for production of a human Smad2/3 protein. Smad2/3 expression levels in selected clones were subsequently analyzed via flow cytometry in experiments done synchronously with microinjection assays to verify that transfected ES cell clones tested in chimeras express roughly equivalent amounts of protein. A representative FACS is shown. (B) Western blot analysis reveals efficient production of Flag-hSmad2(FL), Flag-hSmad2( $\Delta$ exon3), and Flag-hSmad3. The background band that comigrates with Flag-hSmad3 is detectable using the M5 monoclonal alone. (FL) Flag-hSmad2(FL); $(\Delta \mathrm{ex} 3) \quad$ Flag-

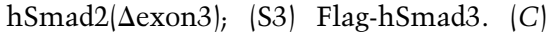
Contribution to the definitive germ layers in E9.5 chimeric embryos. Transverse sections of representative chimeras stained for $\beta$-galactosidase activity at foregut (asterisk), midgut (mg), and hindgut (hg) levels. Wild-type R26.1 as well as KT11Smad2(Aexon3)- and KT15-Smad3-expressing ES cells robustly colonize host embryos and give rise to descendants in all embryonic lineages, including the definitive endoderm. In contrast, Smad2-deficient KT15- and KT11-Smad2(FL)-expressing ES cells fail to contribute to the definitive endoderm, but efficiently form mesoderm and ectoderm. contribute to the definitive endoderm in chimeric embryos (Table 1). As expected, wild-type lacZ-expressing R26.1 ES cells injected into wild-type host embryos efficiently colonize all embryonic germ layers, whereas Smad2-deficient KT15 ES cell descendants are specifically excluded from the definitive endoderm (Fig. 3C; Varlet et al. 1997; Tremblay et al. 2000). Transformants expressing hSmad2(Aexon3) or hSmad3 behave similarly to wild type, with ES cell derivatives (blue cells) interspersed among host wild-type cells along the length of the E9.5 gut epithelium (Table 1; Fig. 3C). It is particularly interesting that hSmad3 expression rescues Smad2 signaling because endogenous Smad3 expression is not compromised in Smad2-deficient ES cells or embryos (Dunn et al. 2004). Thus, increased Smad3 levels appear to compensate for the loss of Smad2 and permit gut colonization. Despite extensive chimerism throughout the embryo, none of the five KT11 subclones expressing $\mathrm{hSmad}$ 2(FL) contribute to the definitive endoderm (Table 1; Fig. 3C). Thus, specification of definitive endoderm is rescued by expression of $\operatorname{Smad} 2(\Delta$ exon 3$)$ or $S m a d 3$ in cells of the anterior primitive streak (APS), but Smad2(FL) expression on its own alone fails to restore Nodal-dependent signaling pathways.

\section{Mutant mice exclusively expressing Smad2(Aexon3) develop normally}

Results above strongly suggest that $\operatorname{Smad} 2(\Delta$ exon 3$)$ but not Smad2(FL) plays an essential role during embryonic 
Table 1. Transfected ES cells expressing Smad2(Dexon3) or Smad3, but not Smad2(FL), contribute to the definitive endoderm in chimeric embryos

\begin{tabular}{lrrc}
\hline $\begin{array}{l}\text { Transfected ES } \\
\text { cell clone }\end{array}$ & $\begin{array}{c}\text { Chimeras } \\
\text { analyzed }\end{array}$ & $\begin{array}{c}\text { Percent } \\
\text { colonization }^{\text {a }}\end{array}$ & $\begin{array}{c}>10 \% \beta \text {-gal } \\
\text { positive } \\
\text { cells in gut }^{\mathrm{a}}\end{array}$ \\
\hline $\begin{array}{l}\text { N-Flag-hSmad2(FL) } \\
\text { AA3 }\end{array}$ & 4 & $5 \%-60 \%$ & 0 \\
BB2 & 14 & $5 \%-80 \%$ & 0 \\
BB6 & 4 & $80 \%-90 \%$ & 0 \\
BB7 & 5 & $10 \%-90 \%$ & 0 \\
CC1 & 4 & $5 \%-70 \%$ & 0 \\
N-Flag-hSmad2(Dexon3) $)^{\mathrm{b}}$ & 6 & $5 \%-50 \%$ & 1 \\
BB2 & 9 & $30 \%-95 \%$ & 8 \\
BB10 & 1 & $20 \%$ & 1 \\
CC1 & 4 & $30 \%-90 \%$ & 4 \\
CC3 & & & \\
N-Flag-hSmad3 & & $30 \%-90 \%$ & 14 \\
G5 & 16 & $40 \%-90 \%$ & 6 \\
H12 & 8 & & \\
\hline
\end{tabular}

a Rescue indicates $>10 \%$ of cells within the gut epithelium were derived from lacZ-expressing ES cell derivatives as assessed in serial sections of chimeric embryos.

${ }^{\mathrm{b}}$ The parent ES cell line was KT11. We analyzed a total of 31 serially sectioned chimeric embryos obtained from five independent $h S m a d 2(F L)$-expressing clones. As for Smad2-deficient ES cells injected into host wild-type blastocysts, the hSmad2(FL)expressing clones extensively contributed to the embryo, but their descendants were specifically excluded from the definitive endoderm.

${ }^{\mathrm{c}}$ The parent ES cell line was KT15.

development. To further evaluate functional contributions made by the short form of Smad2, we engineered a novel Smad2 allele lacking the alternatively spliced exon 3. Smad2 $2^{\text {exon3 }} /+$ mice were derived and subsequently intercrossed to generate animals exclusively producing the Smad2(Aexon3) transcript (Fig. 3A-C). Surprisingly, Smad2 ${ }^{\Delta e x o n 3}$ homozygotes were born at Mendelian ratios, and matured to viable and fertile adults (data not shown). Adult homozygotes fail to display any overt late-onset abnormalities up to 9 mo of age.

To further characterize the Smad2 $2^{\Delta \text { exon3 }}$ mutant allele, total RNA was isolated from the organs of adult littermates and tested for expression of the Smad2(FL) and $S m a d 2(\Delta e x o n 3)$ transcripts. As expected, Smad2 ${ }^{\Delta e x o n 3}$ heterozygotes show increased levels of Smad2(Dexon3) compared to wild type, and Smad2(FL) expression is undetectable in Smad2 $2^{\Delta e x o n 3}$ homozygotes (Fig. 4D). Furthermore, loss of Smad2(FL) expression has no noticeable effect on endogenous Smad3 expression (Fig. 4E; Dunn et al. 2004). We next assessed Smad2(FL) and Smad2(Dexon3) activation upon TGF $\beta 1$ stimulation. The anti-phospho-Smad2 antibody detects low levels of endogenous Smad2(sexon3) protein in wild-type T lymphocytes, whereas this isoform is barely detectable in splenic B cells and HepG2 hepatoma cells (Fig. 4F). Stimulation with TGFß1 leads to prominent Smad2(FL) phosphorylation. Despite roughly equal amounts of Smad2(Dexon3) mRNA expressed by embryonic and adult tissues (Figs. 2A, 4D), the predominant species detectable by Western blot analysis is invariably Smad2(FL) (Fig. 4F), suggesting that Smad2 variants are subject to significant post-transcriptional regulation.

We also evaluated $\operatorname{Smad} 2(\Delta$ exon3) protein levels and function in the absence of Smad3. First, Smad2 $2^{\Delta e x o n 3} /+$ and $S m a d 3^{\text {null }} /+$ mice were mated. Smad2 $2^{\Delta e x o n 3} ; S \operatorname{Smad} 3^{\text {null }}$ double heterozygous progeny were obtained in Mendelian numbers and then intercrossed. To our surprise, $S m a d 2^{\Delta e x o n 3 / \Delta e x o n 3} ; S m a d 3^{\text {null/null }}$ pups were recovered at the predicted Mendelian frequency at weaning (data not shown). These animals are viable and fertile and display no overt hypomorphic phenotypes resulting from Smad2 ${ }^{\text {sexon3 }} / \mathrm{Smad}^{\text {null }}$ genetic interactions, but do, however, develop osteoarthritis characteristic of Smad3 ${ }^{\text {null }}$ homozygous adults (Datto et al. 1999; Yang et al. 2001; data not shown). We next characterized Smad2(sexon3) protein levels and activation in Smad2 ${ }^{\Delta e x o n 3}$; Smad3 ${ }^{\text {null }}$ homozygous mutant mice. As expected, Smad2 ${ }^{\Delta e x o n 3} ; S_{\text {mad3 }}^{\text {null }}$ homozygotes lack phospho-Smad2(FL), but $\operatorname{Smad} 2(\Delta$ exon3) accumulates and is appropriately phosphorylated in response to TGF 1 (Fig. 4F). Collectively, these results show that the Smad2(A exon3) alone is fully capable of transducing the spectrum of TGF $\beta$-related signals in the intact animal.

\section{Human Smad3 expressed under the control of the mouse Smad2 locus partially rescues viability}

Smad3 is not normally expressed within the visceral endoderm, a tissue in which Smad2 is required to pattern

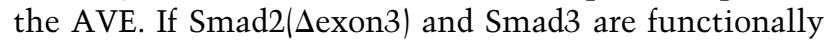
interchangeable, we reasoned that ectopic expression of Smad3 within the visceral endoderm should lead to normal establishment of embryonic A-P polarity and postnatal viability. To test this possibility, we designed a targeting vector to simultaneously delete coding sequences within exon 2 and introduce the $\mathrm{N}$-terminally Flag-tagged $h S m a d 3$ cDNA into the Smad2 locus (Fig. 5A). To be able to distinguish the products arising from the manipulated and wild-type loci and to confirm that the introduced cDNA is appropriately expressed under control of the endogenous regulatory elements, and perhaps more importantly that there is no read-through expression of the endogenous wild-type product, we designed our knock-in alleles using Flag-tagged human Smads that were previously proven to produce biologically active proteins and developed a panel of RNAse protection probes that readily distinguish Flag-tagged human and endogenous mouse Smad transcripts. To avoid disruption of cis-acting regulatory elements that neighbor exon 2, we included the first 44 bp of exon 2 within the $5^{\prime}$ homology arm, while the $3^{\prime}$ homology arm overlaps with last 50 bp of exon 2 . ES cells carrying the initial knock-in allele (Smad2 ${ }^{\text {hSmad3kineo } /+)}$ were identified by Southern blot analysis. Derivative subclones lacking the neomycin selection cassette (Smad2hSmad3ki $/+)$ were recovered following transient transfection with a vector driving expression of Cre recombinase (Fig. 5AC). Smad2 ${ }^{h S m a d 3 k i}$ heterozygotes were intercrossed to 
A

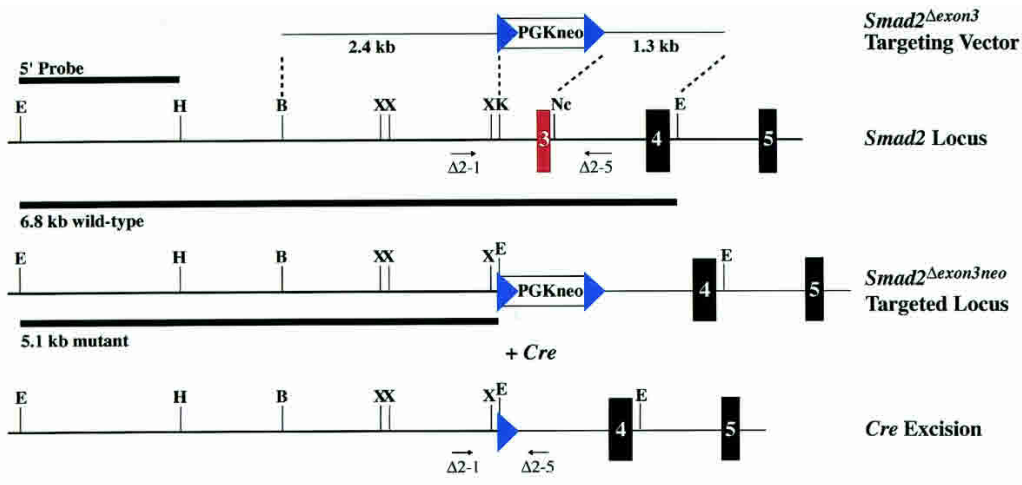

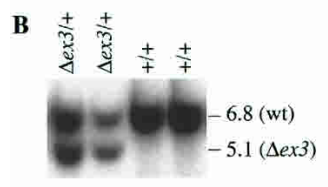

D

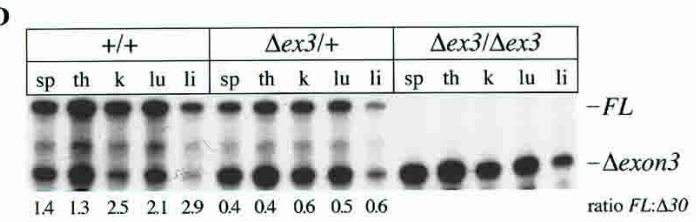

C

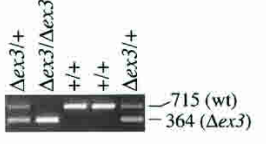

F
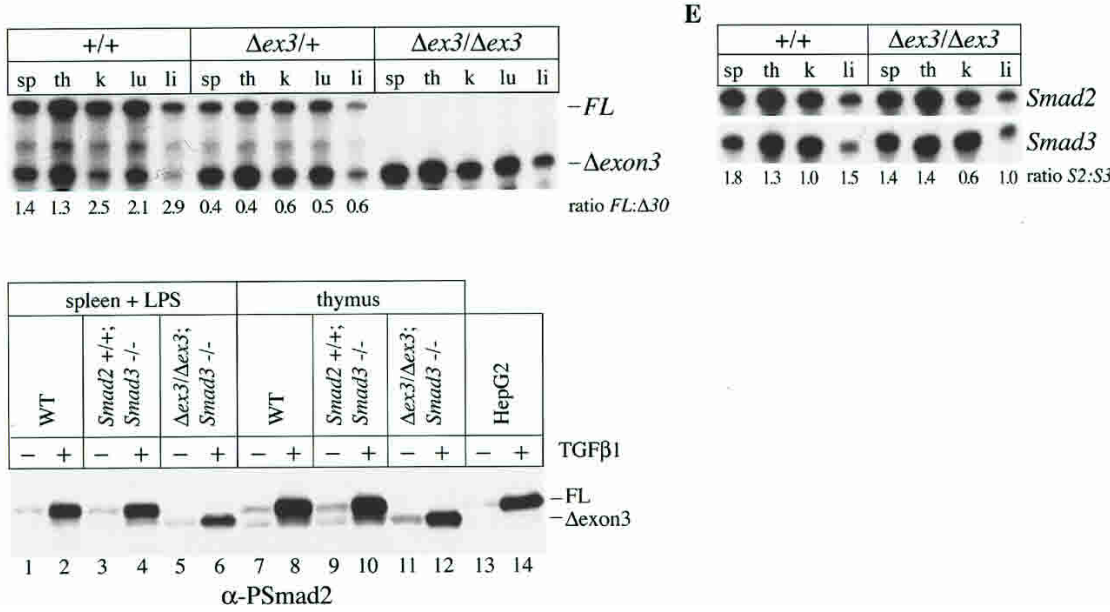

Figure 4. Production of mutant mice exclusively expressing the alternatively spliced Smad2 $\Delta$ exon3 isoform. $(A)$ Strategy used to replace exon 3 with a $\operatorname{lox} P$ (blue triangles)-flanked neomycin-resistance cassette. Targeted clones were identified with a $5^{\prime}$ external probe (black line). (E) EcoRI; (H) HindIII; (B) BamHI; (X) XbaI; (K) KpnI; (Nc) NcoI. (B) Southern blot analysis. The 5' external probe distinguishes $6.8-\mathrm{kb}$ wild-type $(+/+)$ and $5.1-\mathrm{kb}$ targeted $(\Delta e \times 3 /+)$ alleles. $(C)$ PCR genotyping of wild-type, Smad2 $2^{\Delta e x o n 3 /+}(\Delta e x 3 /+)$, and $S m a d 2^{\Delta e x o n 3 / \Delta e x o n 3}(\Delta e x 3 / \Delta e x 3)$ adult mice. The PCR primers in $A$ give rise to products at the indicated sizes. $(D)$ Total RNA from adult tissues was analyzed with RPA probe A (Fig. 1B), which distinguishes Smad2(FL) and Smad2(Dexon3) transcripts. Smad2 ( $\Delta$ exon3) mRNA expression is up-regulated in $S$ mad2 $2^{\Delta e x o n 3} /+$ mice, whereas $S m a d 2(F L)$ transcripts are undetectable in $S m a d 2^{\Delta e x o n 3}$ homozygous mutants. (E) Endogenous Smad2 (probe B) and Smad3 (probe C) expression levels are unperturbed in Smad2 ${ }^{\Delta e x o n 3}$ homozygous mice. The expression ratios indicated by the numbers at the bottoms of the lanes were calculated by scanning the gels in a PhosphorImager and measuring the amount of radioactivity in each band to determine the precise ratios. $(F)$ Western blot analysis using anti-phospho-Smad2 ( $\alpha$-PSmad2) reveals robust Smad2(FL) phosphorylation in wild-type B and T lymphocytes and HepG2 hepatocytes stimulated with TGF $\beta 1$, whereas $\operatorname{Smad} 2\left(\Delta\right.$ exon3) is efficiently phosphorylated in Smad2 $2^{\Delta e x o n 3}$ homozygous mice (lanes 6,12). (sp) Spleen; (th) thymus; (k) kidney; (lu) lung; (li) liver.

generate Smad2 ${ }^{\text {SSmad3ki }}$ homozygous mice. Homozygotes were recovered at a sub-Mendelian frequency $(10 \%$ vs. expected $25 \%$ ) at weaning (Table 2), but those that survive to adulthood are viable and fertile.

To determine whether introduction of the hSmad3 cDNA cassette and accompanying pA signal dysregulates transcription at the Smad2 ${ }^{\text {Smad3ki }}$ locus, we designed RPA probes that distinguish mouse and human Smad3. As expected, a 3'-probe derived from the Flag$h S m a d 3$ cDNA specifically detects $h S m a d 3$ transcripts produced by the $S$ mad2 $2^{\text {hSmad3ki }}$ allele (Fig. 5D). Introduc- tion of the triply repeated SV40 poly(A) cassette into the Smad2 locus greatly attenuates transcription of the remaining downstream Smad2 exons. Thus, residual 3' Smad2 transcripts are barely detectable in Smad2 ${ }^{\text {hSmad3ki/hSmad3ki }}$ adult tissues (Fig. 5D). Importantly, in Smad2 $2^{\text {Smad3ki }} /+$ ES cells and viable adults, $h S m a d 3$ transcripts arising from the manipulated locus are expressed at levels approximately equal to endogenous levels of Smad2 (Fig. 5D).

To investigate the onset of lethality, Smad2 ${ }^{h S m a d 3 k i}$ homozygous embryos were collected at various develop- 
Dunn et al.

Figure 5. Replacement of endogenous Smad2 coding sequences with Smad3. (A) The ATG-containing (arrow) exon 2 of Smad2 was replaced with an N-terminally Flag-tagged human (h) Smad3 cDNA followed by a polyadenylation signal and loxP (blue triangle)-flanked neomycin-resistance cassette. Targeted clones were identified with a $5^{\prime}$ external probe (black line). (B) BamHI; (E) EcoRI; (H) HindIII. (B) Southern blot analysis. The 5' external probe detects $11.5-\mathrm{kb}$ wild-type $(+/+)$ and $5.1-\mathrm{kb}$ targeted $(3 \mathrm{ki} /+)$ alleles. (C) PCR analysis of DNA samples from wild-type, Smad2 $\left.{ }^{h \operatorname{Smad} 3 k i} /+(3 k i)+\right)$, and Smad2 ${ }^{h S m a d 3 k i / h S m a d 3 k i}$ (3ki/3ki) adult mice. PCR primer locations are indicated in $A$. (D) Expression of the introduced $h S m a d 3$ cDNA and endogenous Smad2 by RPA of ES cell, human HepG2 hepatoma, adult tissues, and E12.5 total RNA. (Lanes 3,4) A 3' human Smad3 RPA probe fails to protect mouse mRNA sequences. Similarly, probe B (Fig. 1B) is specific for mouse Smad2 (cf. lanes 2 and 1,3-8). The hSmad3 RPA probe reveals a polymorphism between the HepG2 Smad3 cDNA and the human Smad3 cDNA used in our studies (cf. lanes 1 and 2). (Lanes 1,5-8) Small differences in the ratio of human Smad3 expression from the Smad2 ${ }^{\text {hSmad3ki }}$ allele to Smad2 expression from the wild-type allele are observed in Smad2 ${ }^{h S m a d 3 k i} /+$ ES cells and mice. (Lanes 9-11) Transcription from the remaining downstream exons in the Smad2 ${ }^{h S m a d 3 k i}$ targeted locus is nearly undetectable. The expression ratios indicated by the numbers at the bottoms of the lanes were calculated by scanning the gels in a PhosphorImager and measuring the amount

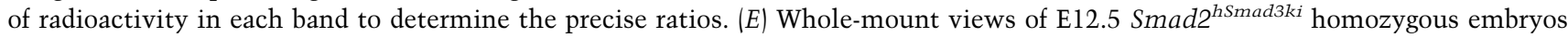
(3ki/3ki) derived from a homozygous parental intercross. Embryos are ordered from overt wild-type morphology (left) to increasingly more severe anterior abnormalities (right). mental stages. From mid- to late gestation, abnormal embryos were easily recognized due to varying degrees of microcephaly, holoprosencephaly, or anencephaly (Fig. 5 F). Histological analysis of six representative mutant embryos at E15.5 and E16.5 reveals limited forebrain and hindbrain development, with no associated defects in the situs of internal organs (data not shown). These anterior patterning defects closely resemble those arising from modulation of Nodal signaling within the APS (Nomura and Li 1998; Song et al. 1999).
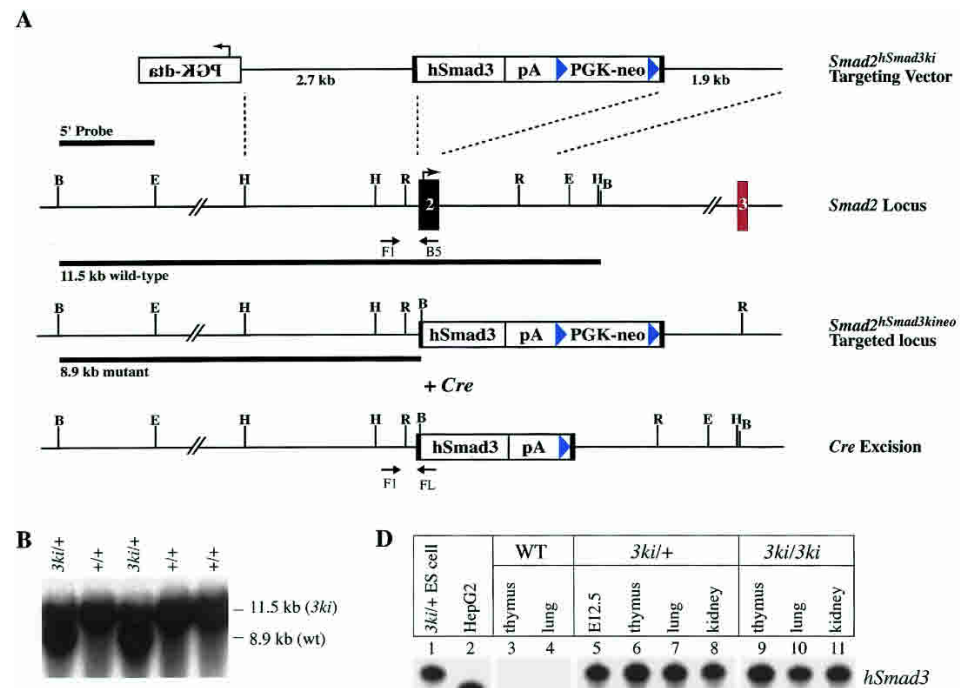

D
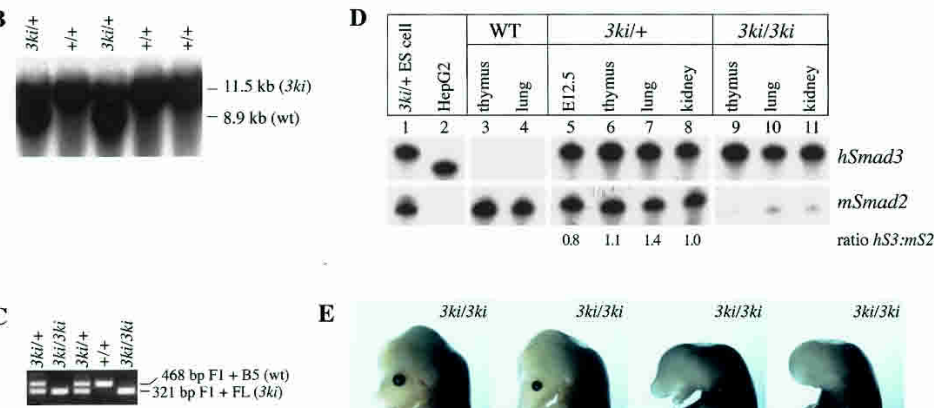

E

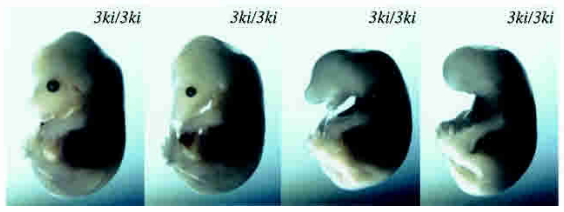

One plausible explanation that accounts for the hypomorphic nature of the Smad2 ${ }^{h S m a d 3 k i}$ allele is that the presence of the Flag epitope impacts the DNA binding or nuclear import functions within the MH1 domain, or alternatively augments the autoinhibitory interactions between the MH1 and MH2 domains (Hata et al. 1997). Additionally, Smad2 contains a 10-amino acid glycinerich insert within the extreme $\mathrm{N}$-terminal $\mathrm{MH} 1$ domain not found in Smad3 (Fig. 1B) that potentially regulates selection of DNA-binding partners. Finally, the intro-

Table 2. Summary of phenotypic disturbances observed in Smad2 $\mathrm{h}^{\mathrm{hSmad} 3 \mathrm{ki}}$ intercross progeny

\begin{tabular}{|c|c|c|c|c|c|}
\hline Age & $+/+$ & Smad2hSmad3ki $/+$ & $\begin{array}{l}\text { Smad2hSmad3ki } / \\
\text { Smad2hSmad3ki }\end{array}$ & $\mathrm{RS} / \mathrm{ED}^{\mathrm{a}}$ & $\mathrm{AAD}^{\mathrm{b}}$ \\
\hline E9.5 & 15 & 16 & 6 & 4 & 0 \\
\hline E15.5 & 4 & 11 & 4 & 0 & 2 \\
\hline E16.5 & 15 & 28 & 8 & 6 & 4 \\
\hline Total $(\%)^{\mathrm{c}}$ & $34(32 \%)$ & $55(51 \%)$ & $18(17 \%)$ & & \\
\hline Weanlings $(\%)^{\mathrm{c}}$ & $33(32 \%)$ & $60(58 \%)$ & $10(10 \%)$ & & \\
\hline
\end{tabular}

${ }^{a}$ The presence of resportion sites (RS) or empty decidua (ED) at the time of dissection suggests that some mutants die with more severe developmental abnormalities. Insufficient material for genotype determination.

${ }^{b}$ Number of Smad2hSmad3ki/hSmad3ki embryos with abnormal anterior development (AAD).

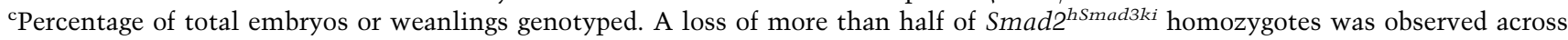
more than three generations of breeding. The surviving homozygotes show normal fertility, and in homozygous crosses, $\sim 50 \%$ of the embryos develop normally, whereas the others die in utero or at birth due to anterior patterning defects. Since the $\operatorname{Smad} 2^{\text {hSmad } 3 k i}$ mice were maintained on a mixed $(\mathrm{C} 57 \mathrm{BL} / 6 \mathrm{~J} \times 129 \mathrm{~Sv} / / \mathrm{Ev})_{\mathrm{F} 1}$ background, these distinct phenotypes may be due to genetic background differences. 
duction of the human versus mouse Smad3 cDNA by homologous recombination could lead to subtle functional differences, as has been recently illustrated with mice humanized for the EGF receptor (Sibilia et al. 2003). Nevertheless, the fact that a significant number of Smad2 ${ }^{\text {hSmad } 3 k i}$ homozygotes are viable provides compelling evidence that $\operatorname{Smad} 2(\Delta$ exon 3$)$ and Smad3 are the key regulators of TGF $\beta$-signaling pathways.

\section{Discussion}

\section{Smad2(FL) is nonessential for viability}

Recent transcriptional activation assays comparing Smad2-deficient and Smad3-deficient mouse embryonic fibroblasts (MEFs) have identified distinct Smad2 and Smad3 downstream target genes. For example, Smad7 expression requires Smad3, whereas matrix metalloproteinase 2 regulation is dependent on Smad2 (Piek et al. 2001). Moreover, transcriptional profiling of these mutant MEFs reveals that in response to TGF $\beta$ stimulation, Smad 3 activates a set of immediate-early genes that encode signal transducers and transcriptional regulators, while Smad2 appears to negatively modulate a number of these same genes (Yang et al. 2003). Similarly, morpholino knock-down experiments in $\mathrm{HaCaT}$ keratinocytes demonstrate that Smad3 serves as the principal effector of TGF $\beta$-mediated growth arrest, while loss of Smad2 has no detectable effect (Kretschmer et al. 2003). Thus, considerable evidence suggests that the closely related Smad2 and Smad3 effectors are not redundant but, rather, have distinct activities and transcriptional targets. This difference is likely due to the presence of the unique 30 -amino acid insert found just $\mathrm{N}$-terminal to the $\beta$-hairpin in the Smad2 MH1 domain.

Here, we find quite unexpectedly that replacing the mouse Smad2 gene with a Flag-tagged human Smad3 cDNA results in adult viability. Thus, Smad3 expressed under the control of the endogenous Smad2 locus correctly regulates the panoply of target genes that lies downstream of TGF $\beta$-related signals and is required for patterning the early embryo. This result is especially surprising since some of these targets such as Nodal and Pitx2 were previously characterized by in vitro assays to be Smad2-dependent (Saijoh et al. 2000; Shiratori et al. 2001). In particular, we have shown that Smad2 is absolutely required in the visceral endoderm to specify the AVE (Waldrip et al. 1998). Smad3 is not normally expressed in this tissue. The ectopic expression of Smad3 by the Smad2 ${ }^{\text {hSmad3ki }}$ allele restores Smad2 signaling and unequivocally demonstrates that Smad3 can activate the genetic program that specifies the AVE signaling center. Thus, irrespective of well-documented differences in DNA binding, nuclear import, oligomeric states, and interacting partners, the present experiments provide clear evidence that Smad2 and Smad3 are functionally interchangeable in the intact animal. In particular, it is the Smad2(Dexon3) transcript generated by alternative splicing that contributes essential activities, whereas Smad2(FL) is nonessential.

\section{Smad2 and Smad3 genetic interactions revisited}

Smad2 ${ }^{+/-}$; Smad3 ${ }^{-/-}$mouse embryos display anterior patterning defects identical to conditional loss of Smad2 within the epiblast (Vincent et al. 2003; Dunn et al. 2004). These strikingly similar phenotypes result from the loss of anterior definitive endoderm and prechordal plate that emerge from the APS during early gastrulation, and suggest that Smad2 serves as the predominant intracellular effector of Nodal signaling in the early embryo (Dunn et al. 2004). In other words, Smad3 levels within the epiblast of Smad2 conditional mutant embryos as well as in chimeras mostly composed of Smad2deficient ES cell descendants are inadequate to compensate for the loss of Smad2. We were unable to precisely determine the expression ratios of Smad2(FL), Smad2(Aexon3), and Smad3 within the small population of epiblast cells that ingresses through the APS, but our results nevertheless demonstrate that the $\operatorname{Smad} 2(\Delta$ exon3) isoform acting alone can correctly specify APS derivatives that come to underlie and pattern the anterior neural plate. Our results therefore suggest that the failure to pattern the APS in these mutant contexts results from

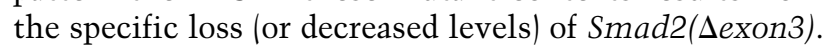

Several elegant studies with Activin and TGF $\beta 1$ have shown that the number of occupied cell surface receptors is proportional to the nuclear concentration of activated Smad2 (Shimizu and Gurdon 1999; Bourillot et al. 2002; Inman et al. 2002). Decreased concentrations of intracellular Smads are therefore predicted to significantly impact target gene regulation. Consistent with this, our previous work shows that the population of cells most sensitive to fluctuating Nodal levels resides within the APS (Norris et al. 2002; Vincent et al. 2003; Dunn et al. 2004). In the wild-type embryo, coexpression of the short Smad2(Aexon3) isoform and Smad3 may serve to selectively amplify Nodal signals in these discrete cell types.

We also engineered Smad2 ${ }^{h S m a d 2(F L)}$ and $S m a d 2^{h S m a d 2(\Delta e x o n 3)}$ knock-in mutations via the identical strategy described above for the construction of the Smad2 ${ }^{\text {hSmad } 3 k i}$ allele. Disappointingly, both these alleles recapitulated the Smad2-null phenotype, with characteristic failure to establish A-P polarity and formation of abundant extraembryonic mesoderm at E8.5. Homozygous mutant embryos were found to express FlaghSmad2(FL) and Flag-hSmad2(Aexon3) proteins at levels equivalent to wild-type Smad2 (data not shown). In contrast, microinjection experiments analyzing transfected Smad2-deficient ES cells expressing Flag-tagged Smad2 isoforms for their ability to reconstitute chimeras exploited a strong ubiquitous promoter to drive expression throughout development, and in this case rescue of gut colonization only requires Smad2 activity over a narrow time window and at restricted tissue sites. In contrast, complete rescue of normal embryonic development requires appropriate expression of knock-in alleles under control of the endogenous regulatory elements governing wild-type Smad2 levels at earlier egg cylinder stages in the visceral endoderm and the epiblast. The inability of Flag-tagged human Smad2 isoforms to rescue early em- 
bryos is, indeed, quite perplexing. It seems most likely that then $\mathrm{N}$-terminal Flag-epitope more strongly interferes with Smad2 than Smad3 functional activities. Nevertheless, the present positive results conclusively demonstrate that roughly half of the Smad2 ${ }^{\text {Smad3ki homo- }}$ zygotes develop normally and are viable and fertile. Thus, we conclude that Smad3 can activate all essential TGF $\beta /$ Nodal/Activin signaling pathways.

\section{Evolution of vertebrate Smad2 and Smad3}

Nodal homologs have been identified in both chordates and echinoderms (Morokuma et al. 2002; Yu et al. 2002; Duboc et al. 2004). In sea urchins, Nodal expression in the presumptive oral ectoderm is absolutely required for the development of oral structures and regulates $\mathrm{Bmp2/}$ 4, which acts downstream of Nodal to specify aboral fates (Duboc et al. 2004). This signaling pathway parallels the situation in mice in which $B m p 4$ expression in the extraembryonic ectoderm is positively regulated by Nodal signals emanating from the proximal epiblast (Brennan et al. 2001; Beck et al. 2002). Thus, we propose that Nodal and its requisite intracellular effector Smad2 are components of an evolutionarily conserved signaling paradigm for organizing the basic body plan. Indeed, the sea urchin genome project has recently identified a Smad2/3-related gene (GenBank Trace Repository; http://sugp.caltech.edu).

In mice, Smad2 is tightly linked to Smad4 and Smad7, which encodes an inhibitory Smad, on chromosome 18, while Smad3 is linked to Smad6, a second inhibitory Smad, on chromosome 9 (http://www.ensembl.org). This parallel genomic organization is also conserved in humans (OMIM). It therefore appears that Smad3 arose in the vertebrate lineage due to a partial duplication of an ancestral "Smad" cassette. Since Smad3-null mutants exhibit phenotypes primarily confined to the regulation of the immune system, we therefore speculate that this duplication event coincides with the emergence of adaptive immunity among the jawed vertebrates (Datto et al. 1999; Yang et al. 1999; Kasahara et al. 2004). This prediction is also consistent with our dose-dependency model, which emphasizes the predominant role of Smad2 in axis specification and germ-layer formation in the early embryo, with amplifying or reinforcing activity provided by Smad3 in the primitive streak (Dunn et al. 2004). Indeed, a high percentage of chimeras derived from Smad2-deficient ES cells, whose definitive endoderm is wild type in origin, are overtly normal and fertile (our unpublished results).

Rare inactivating mutations in Smad2 have been identified in a proportion of human colorectal and lung cancers, whereas similar genetic lesions in Smad3 have not been characterized (Arai et al. 1998; Derynck et al. 2001; Siegel and Massagué 2003). It will be interesting to learn whether the tumor-suppressor activity of Smad2 is contributed by the short $\operatorname{Smad} 2(\Delta$ exon3) isoform. In a recent study, reduced Smad3 levels were observed in more than one-third of gastric tumors (Han et al. 2004). The loss of TGF $\beta$-dependent cell cycle arrest and promotion of tu- morigenesis may therefore be accomplished by the combined levels of $\operatorname{Smad} 2(\Delta$ exon 3$)$ and Smad3 falling below a threshold that normally ensures the activation of the cyclin-dependent kinase inhibitors $p 15$ and $p 21$ and the maintenance of cytostasis (Feng et al. 2000; Pardali et al. 2000). Release from the antiproliferative effects of TGF $\beta$ may also occur by direct phosphorylation of Smad2(Aexon3)/Smad3 by the cyclin-dependent kinases, which inhibits their transcriptional activity (Matsuura et al. 2004).

\section{Splicing among the Smad genes}

To date, alternative splicing has been described for the Smad2, Smad3, Smad4, Smad5, and Smad8 genes (Takenoshita et al. 1998; Nishita et al. 1999; Pierreux et al. 2000; Kjellman et al. 2004). For example, six Smad4 splice variants have been identified that differ in the length of the linker region. Each of these isoforms retains its ability to interact with Smad2 and Smad3, but only three are capable of robust transcriptional activation (Pierreux et al. 2000). We speculate that structurally distinct Smad protein isoforms equip target cell populations with a versatile intracellular machinery to accommodate the array of extracellular TGF $\beta$-related signals, and provide an important mechanism for modulating target gene activity (Lareau et al. 2004). A comprehensive understanding of the individual contributions of the growing Smad proteome awaits future genetic analysis.

\section{Materials and methods}

Derivation of ES cell lines and production of chimeric embryos

N-terminally Flag-tagged human (h) Smad2(FL), Smad2( $\Delta 30)$, and Smad3 cDNA cassettes (Yagi et al. 1999) were subcloned into a modified version of pCAGGS (Niwa et al. 1991). Each expression vector was linearized and electroporated into either the KT11 or KT15 Smad2 ${ }^{\text {Robm1 }}$ homozygous ES cell lines that constitutively express the Rosa26 lacZ reporter (Tremblay et al. 2000). Hygromycin-resistant clones were initially screened for expression of the introduced construct by flow cytometry. For cytoplasmic staining, cells were treated with $10 \%$ formalin and extensively washed with PBS containing $0.1 \%$ saponin. STO feeder cells were eliminated from the analysis by appropriate gating. Primary antibodies (Ab) included mouse anti-Smad2/3 (Transduction), which cross-reacts with hSmad2/3, and, as a control, mouse anti- $\beta$-galactosidase (Promega). The secondary reagent used was FITC-conjugated goat anti-mouse IgG $(\mathrm{H}+\mathrm{L}$; Caltag). Fluorescence was analyzed using a FACScan flow cytometer, and the data are displayed as cell number versus log fluorescence. The cell lines developed in this study (Table 1) as well as the control ES cell lines R26.1 (Varlet et al. 1997) and KT15 were separately injected into host ICR (Taconic) blastocysts (Nagy et al. 2003). Manipulated embryos were recovered between E9.0 and E10.0, X-gal stained in whole mount, embedded in paraffin wax, and serially sectioned according to standard procedures.

\section{Generation of Smad2 mutant alleles}

Deletion of Smad2 coding exon 3. A 488-bp KpnI-NcoI fragment of the Smad2 gene that contains the alternatively spliced 
exon 3 was replaced with a loxP-flanked PGK-neomycin (neo) resistance cassette by homologous recombination in ES cells. The targeting vector contains $2.4-\mathrm{kb} 5^{\prime}$ and $1.3-\mathrm{kb} 3^{\prime}$ homology arms. Linearized vector was electroporated into CCE ES cells, and drug-resistant colonies were genotyped by Southern blot analysis using either a $5^{\prime}$-external $1.6-\mathrm{kb}$ EcoRI-HindIII probe (Fig. 3B; Nomura and Li 1998) or a 3'-internal 962-bp SpeI-EcoRI probe with KpnI digestion of genomic DNA. Four correctly targeted clones out of 2200 were identified.

Introduction of Smad3 coding sequences into the mouse Smad2 locus. The ATG-containing exon 2 of Smad2 was disrupted by homologous recombination with a vector containing $2.7 \mathrm{~kb}$ of $5^{\prime}$ homology, followed by an $\mathrm{N}$-terminally Flag-tagged human Smad3 cDNA (above), a triply repeated SV40 polyadenylation cassette to ensure transcriptional termination (Maxwell et al. 1989), a loxP-flanked PGK-neo cassette, and $1.86 \mathrm{~kb}$ of 3 ' homology. A PGK-dta cassette was used for negative selection. Linearized vector was electroporated into CCE ES cells, and drug-resistant colonies were genotyped by Southern blot analysis with a $5^{\prime}$-external probe as previously described (Waldrip et al. 1998) or a 3'-internal 587-bp EcoRV-SpeI probe with SpeI digestion of genomic DNA. Five correctly targeted clones out of 600 were identified.

For both Smad2 alleles, targeted clones were transiently transfected with Cre recombinase. Loss of the neo cassette was verified by Southern analysis with a 630-bp PstI-XbaI neo probe. At least two independently targeted ES cell clones were used to generate germline chimeric mice.

\section{Mouse strains and genotyping procedures}

Smad2 $2^{\text {exon3 }} /+$ and Smad2 ${ }^{\text {Smad3ki }} /+(129 / \mathrm{Sv} / / \mathrm{Ev} \times \mathrm{C} 57 \mathrm{BL} / 6)_{\mathrm{F} 1}$ mice were outcrossed to ICR, and then each line was maintained by intercrossing. Outbred Smad2 $2^{\Delta e x o n 3 / \Delta e x o n 3}$ and Smad3 $3^{\text {null/null }}$ mice were intercrossed. The PCR primers used to detect the Smad2 $2^{\Delta e x o n 3}$ allele were $\Delta 2-1,5^{\prime}$-GAACTGATCCTCCTGTT TCC-3'; and $\Delta 2$-B5, 5' -TGGCACGCTGATA CTTTACACG-3'; with an annealing temperature of $59^{\circ} \mathrm{C}$ for 35 cycles (Fig. 3C). The primers used to detect the $S$ mad $2^{\text {hSmad3ki }}$ allele were Smad2com, 5' -AGTTAATTGCCCAGAGCGTTGACA-3' ${ }^{\prime}$ FLAG1, 5' -CATCGTCCTTGTAGTCCATG-3'; and B5, 5' -CACTTTTC TTCCTGTCCATTCTGC-3'; with an annealing temperature of $58^{\circ} \mathrm{C}$ for 35 cycles (Fig. 4C). Detection of the Smad $3^{\text {null }}$ allele was as previously described (Dunn et al. 2004).

\section{Ribonuclease protection assays}

Total RNA from CCE ES cells, mouse embryos at various stages, or adult organs was prepared using Trizol (Invitrogen). Ribonuclease protection assays were performed on $10 \mu \mathrm{g}$ of total RNA (RPA III kit; Ambion). The following probes were used: a 3' 221-bp BglII-BamHI fragment from mouse Smad2 (Waldrip et al. 1998; Dunn et al. 2004); a 5' 325-bp PCR-derived probe from the mouse Smad2 cDNA that protects coding exons 2 and 3 (5'-primer, 5'-CGGAATTCGCATGTCGTCCATCTTGCCA TT-3'; 3'-primer, 5'-CGGGATCCGCTGGTTTGTTCAGAGA AGC); a 3' 237-bp HincII fragment from mouse Smad3; and a 3 '-probe corresponding to the last 255 bp of human Smad3. RPA products were separated on 5\% PAGE gels, exposed to film, and quantitated by PhosphorImager.

\section{$B$ - and T-cell stimulation with hTGFß}

Spleen cell suspensions depleted of erythrocytes were incubated at $37^{\circ} \mathrm{C}$ in B-cell medium containing LPS $(50 \mu \mathrm{g} / \mathrm{mL}$; Difco Laboratories) and hTGF $\beta(5 \mathrm{ng} / \mathrm{mL} ; \mathrm{R} \& D$ Systems $)$ at a density of $5 \times 10^{7}$ cells $/ \mathrm{mL}$ for $48 \mathrm{~h}$. Thymocytes were incubated at $37^{\circ} \mathrm{C}$ in T-cell medium containing hTGF $\beta-1(5 \mathrm{ng} / \mathrm{mL})$ for $1 \mathrm{~h}$ at a density of $4 \times 10^{7}$ cells $/ \mathrm{mL}$. Cell suspensions were harvested, washed with PBS containing 2\% FCS and antibiotics, and lysed in buffer containing protease and phosphatase inhibitors (Sigma). After incubation on ice, extracts were cleared of nuclei and debris by centrifugation.

\section{Protein purification and Western blotting}

Protein extracts $(50 \mu \mathrm{g})$ derived from ES cells, COS cells transfected with the pCAGGS-N-Flag-hSmad expression constructs (Lipofectamine 2000), and B and T cells were mixed with an equal volume of $2 \times$ Laemmli buffer and then separated on a $10 \%$ SDS-PAGE gel followed by transfer to nitrocellulose (Protran). ES cell and COS cell extracts were analyzed with the anti-Flag M5 monoclonal (Sigma) in combination with an HRP-conjugated sheep anti-mouse secondary (Amersham); stimulated B, $\mathrm{T}$, and HepG2 cells with a rabbit anti-phospho-smad2 (Cell Signaling), followed by HRP-conjugated donkey anti-rabbit secondary (Amersham). Blots were developed by chemiluminescence using ECL (Amersham).

\section{Acknowledgments}

We thank Debbie Pelusi for genotyping assistance. We are grateful to Gerald Chu for histological analysis of Smad2 ${ }^{\text {hSmad3ki }}$ homozygous embryos; and Masahiro Kawabata, Jun-ichi Miyazaki, Leif Oxburgh, and Peter Holland for plasmid reagents, insightful discussions, and protocols. N.R.D. was supported by a postdoctoral fellowship from the NICHD. This work was supported by grants from the NIH to E.J.R.

\section{References}

Arai, T., Akiyama, Y., Okabe, S., Ando, M., Endo, M., and Yuasa, Y. 1998. Genomic structure of the human Smad3 gene and its infrequent alterations in colorectal cancers. Cancer Lett. 122: 157-163.

Beck, S., Le Good, J.A., Guzman, M., Ben Haim, N., Roy, K., Beermann, F., and Constam, D.B. 2002. Extraembryonic proteases regulate Nodal signalling during gastrulation. Nat. Cell Biol. 4: 981-985.

Bourillot, P.Y., Garrett, N., and Gurdon, J.B. 2002. A changing morphogen gradient is interpreted by continuous transduction flow. Development 129: 2167-2180.

Brennan, J., Lu, C.C., Norris, D.P., Rodriguez, T.A., Beddington, R.S., and Robertson, E.J. 2001. Nodal signalling in the epiblast patterns the early mouse embryo. Nature 411: 965 969.

Cheng, S.K., Olale, F., Bennett, J.T., Brivanlou, A.H., and Schier, A.F. 2003. EGF-CFC proteins are essential coreceptors for the TGF- $\beta$ signals Vg1 and GDF1. Genes \& Dev. 17: 31-36.

Chou, W.C., Prokova, V., Shiraishi, K., Valcourt, U., Moustakas, A., Hadzopoulou-Cladaras, M., Zannis, V.I., and Kardassis, D. 2003. Mechanism of a transcriptional cross talk between transforming growth factor- $\beta$-regulated Smad3 and Smad4 proteins and orphan nuclear receptor hepatocyte nuclear factor-4. Mol. Biol. Cell 14: 1279-1294.

Datto, M.B., Frederick, J.P., Pan, L., Borton, A.J., Zhuang, Y., and Wang, X.F. 1999. Targeted disruption of Smad3 reveals an essential role in transforming growth factor $\beta$-mediated signal transduction. Mol. Cell. Biol. 19: 2495-2504.

Dehal, P., Satou, Y., Campbell, R.K., Chapman, J., Degnan, B., De Tomaso, A., Davidson, B., Di Gregorio, A., Gelpke, M., 
Goodstein, D.M., et al. 2002. The draft genome of Ciona intestinalis: Insights into chordate and vertebrate origins. Science 298: 2157-2167.

Dennler, S., Huet, S., and Gauthier, J.M. 1999. A short aminoacid sequence in $\mathrm{MH} 1$ domain is responsible for functional differences between Smad2 and Smad3. Oncogene 18: 16431648.

Derynck, R., Akhurst, R.J., and Balmain, A. 2001. TGF- $\beta$ signaling in tumor suppression and cancer progression. Nat. Genet. 29: 117-129.

Di Guglielmo, G.M., Le Roy, C., Goodfellow, A.F., and Wrana, J.L. 2003. Distinct endocytic pathways regulate TGF- $\beta$ receptor signalling and turnover. Nat. Cell Biol. 5: 410-421.

Duboc, V., Rottinger, E., Besnardeau, L., and Lepage, T. 2004. Nodal and BMP2/4 signaling organizes the oral-aboral axis of the sea urchin embryo. Dev. Cell 6: 397-410.

Dunn, N.R., Vincent, S.D., Oxburgh, L., Robertson, E.J., and Bikoff, E.K. 2004. Combinatorial activities of Smad2 and Smad3 regulate mesoderm formation and patterning in the mouse embryo. Development 131: 1717-1728.

Faure, S., Lee, M.A., Keller, T., ten Dijke, P., and Whitman, M. 2000. Endogenous patterns of TGF $\beta$ superfamily signaling during early Xenopus development. Development 127: 2917-2931.

Feng, X.H., Lin, X., and Derynck, R. 2000. Smad2, Smad3 and Smad4 cooperate with Sp1 to induce p15(Ink4B) transcription in response to TGF- $\beta$. EMBO J. 19: 5178-5193.

Han, S.U., Kim, H.T., Seong, D.H., Kim, Y.S., Park, Y.S., Bang, Y.J., Yang, H.K., and Kim, S.J. 2004. Loss of the Smad3 expression increases susceptibility to tumorigenicity in human gastric cancer. Oncogene 23: 1333-1341.

Hata, A., Lo, R.S., Wotton, D., Lagna, G., and Massagué, J. 1997. Mutations increasing autoinhibition inactivate tumour suppressors Smad2 and Smad4. Nature 388: 82-87.

Heyer, J., Escalante-Alcalde, D., Lia, M., Boettinger, E., Edelmann, W., Stewart, C.L., and Kucherlapati, R. 1999. Postgastrulation Smad2-deficient embryos show defects in embryo turning and anterior morphogenesis. Proc. Nat1. Acad. Sci. 96: $12595-12600$.

Inman, G.J., Nicolas, F.J., and Hill, C.S. 2002. Nucleocytoplasmic shuttling of Smads 2, 3, and 4 permits sensing of TGF- $\beta$ receptor activity. Mol. Cell 10: 283-294.

Jayaraman, L. and Massagué, J. 2000. Distinct oligomeric states of SMAD proteins in the transforming growth factor- $\beta$ pathway. J. Biol. Chem. 275: 40710-40717.

Kasahara, M., Suzuki, T., and Pasquier, L.D. 2004. On the origins of the adaptive immune system: Novel insights from invertebrates and cold-blooded vertebrates. Trends Immunol. 25: 105-111.

Kjellman, C., Honeth, G., Jarnum, S., Lindvall, M., Darabi, A., Nilsson, I., Edvardsen, K., Salford, L.G., and Widegren, B. 2004. Identification and characterization of a human smad3 splicing variant lacking part of the linker region. Gene 327: 141-152.

Kretschmer, A., Moepert, K., Dames, S., Sternberger, M., Kaufmann, J., and Klippel, A. 2003. Differential regulation of TGF- $\beta$ signaling through Smad2, Smad3 and Smad4. Oncogene 22: 6748-6763.

Kurisaki, A., Kose, S., Yoneda, Y., Heldin, C.H., and Moustakas, A. 2001. Transforming growth factor- $\beta$ induces nuclear import of Smad3 in an importin- $\beta 1$ and Ran-dependent manner. Mol. Biol. Cell 12: 1079-1091.

Labbé, E., Silvestri, C., Hoodless, P.A., Wrana, J.L., and Attisano, L. 1998. Smad2 and Smad3 positively and negatively regulate TGF $\beta$-dependent transcription through the forkhead DNA-binding protein FAST2. Mol. Cell 2: 109-120.
Lareau, L.F., Green, R.E., Bhatnagar, R.S., and Brenner, S.E. 2004. The evolving roles of alternative splicing. Curr. Opin. Struct. Biol. 14: 273-282.

Lebrun, J.J., Takabe, K., Chen, Y., and Vale, W. 1999. Roles of pathway-specific and inhibitory Smads in activin receptor signaling. Mol. Endocrinol. 13: 15-23.

Liu, F. 2003. Receptor-regulated Smads in TGF- $\beta$ signaling. Front Biosci. 8: s1280-s1303.

Liu, Y., Festing, M., Thompson, J.C., Hester, M., Rankin, S., El-Hodiri, H.M., Zorn, A.M., and Weinstein, M. 2004. Smad2 and Smad3 cooperatively regulate craniofacial and endodermal development. Dev. Biol. 270: 411-426.

Massagué, J. and Wotton, D. 2000. Transcriptional control by the TGF- $\beta /$ Smad signaling system. EMBO J. 19: 1745-1754.

Massagué, J., Blain, S.W., and Lo, R.S. 2000. TGF $\beta$ signaling in growth control, cancer, and heritable disorders. Cell 103: 295-309.

Matsuura, I., Denissova, N.G., Wang, G., He, D., Long, J., and Liu, F. 2004. Cyclin-dependent kinases regulate the antiproliferative function of Smads. Nature 430: 226-231.

Maxwell, I.H., Harrison, G.S., Wood, W.M., and Maxwell, F. 1989. A DNA cassette containing a trimerized SV40 polyadenylation signal which efficiently blocks spurious plasmid-initiated transcription. Biotechniques 7: 276-280.

Miyazawa, K., Shinozaki, M., Hara, T., Furuya, T., and Miyazono, K. 2002. Two major Smad pathways in TGF- $\beta$ superfamily signalling. Genes Cells 7: 1191-1204.

Morokuma, J., Ueno, M., Kawanishi, H., Saiga, H., and Nishida, H. 2002. HrNodal, the ascidian nodal-related gene, is expressed in the left side of the epidermis, and lies upstream of HrPitx. Dev. Genes Evol. 212: 439-446.

Nagy, A., Gertsentein, M., Vintersten, K., and Behringer, R. 2003. Manipulating the mouse embryo. Cold Spring Harbor Laboratory Press, Cold Spring Harbor, New York.

Newfeld, S.J., Wisotzkey, R.G., and Kumar, S. 1999. Molecular evolution of a developmental pathway: Phylogenetic analyses of transforming growth factor- $\beta$ family ligands, receptors and Smad signal transducers. Genetics 152: 783-795.

Nishita, M., Ueno, N., and Shibuya, H. 1999. Smad8B, a Smad8 splice variant lacking the SSXS site that inhibits Smad8mediated signalling. Genes Cells 4: 583-591.

Niwa, H., Yamamura, K., and Miyazaki, J. 1991. Efficient selection for high-expression transfectants with a novel eukaryotic vector. Gene 108: 193-199.

Nomura, M. and Li, E. 1998. Smad2 role in mesoderm formation, left-right patterning and craniofacial development. $\mathrm{Na}$ ture 393: 786-790.

Norris, D.P., Brennan, J., Bikoff, E.K., and Robertson, E.J. 2002. The Foxh1-dependent autoregulatory enhancer controls the level of Nodal signals in the mouse embryo. Development 129: 3455-3468.

Osada, S.I., Saijoh, Y., Frisch, A., Yeo, C.Y., Adachi, H., Watanabe, M., Whitman, M., Hamada, H., and Wright, C.V. 2000. Activin/Nodal responsiveness and asymmetric expression of a Xenopus Nodal-related gene converge on a FAST-regulated module in intron 1. Development 127: 2503-2514.

Pardali, K., Kurisaki, A., Moren, A., ten Dijke, P., Kardassis, D., and Moustakas, A. 2000. Role of Smad proteins and transcription factor $\mathrm{Sp} 1$ in $\mathrm{p} 21^{\text {Waf1/Cip } 1}$ regulation by transforming growth factor- $\beta$. J. Biol. Chem. 275: 29244-29256.

Parisi, S., D'Andrea, D., Lago, C.T., Adamson, E.D., Persico, M.G., and Minchiotti, G. 2003. Nodal-dependent Cripto signaling promotes cardiomyogenesis and redirects the neural fate of stem cells. J. Cell Biol. 163: 303-314.

Piek, E., Ju, W.J., Heyer, J., Escalante-Alcalde, D., Stewart, C.L., Weinstein, M., Deng, C., Kucherlapati, R., Bottinger, E.P., 
and Roberts, A.B. 2001. Functional characterization of transforming growth factor $\beta$ signaling in Smad2- and Smad3deficient fibroblasts. J. Biol. Chem. 276: 19945-19953.

Pierreux, C.E., Nicolas, F.J., and Hill, C.S. 2000. Transforming growth factor $\beta$-independent shuttling of Smad4 between the cytoplasm and nucleus. Mol. Cell. Biol. 20: 9041-9054.

Reguly, T. and Wrana, J.L. 2003. In or out? The dynamics of Smad nucleocytoplasmic shuttling. Trends Cell Biol. 13: 216-220.

Saijoh, Y., Adachi, H., Sakuma, R., Yeo, C.Y., Yashiro, K., Watanabe, M., Hashiguchi, H., Mochida, K., Ohishi, S., Kawabata, M., et al. 2000. Left-right asymmetric expression of lefty 2 and nodal is induced by a signaling pathway that includes the transcription factor FAST2. Mol. Cell 5: 35-47.

Seoane, J., Le, H.V., Shen, L., Anderson, S.A., and Massagué, J. 2004. Integration of Smad and forkhead pathways in the control of neuroepithelial and glioblastoma cell proliferation. Cell 117: 211-223.

Shi, Y. and Massagué, J. 2003. Mechanisms of TGF- $\beta$ signaling from cell membrane to the nucleus. Cell 113: 685-700.

Shi, Y., Wang, Y.F., Jayaraman, L., Yang, H., Massagué, J., and Pavletich, N.P. 1998. Crystal structure of a Smad MH1 domain bound to DNA: Insights on DNA binding in TGF- $\beta$ signaling. Cell 94: 585-594.

Shimizu, K. and Gurdon, J.B. 1999. A quantitative analysis of signal transduction from activin receptor to nucleus and its relevance to morphogen gradient interpretation. Proc. Natl. Acad. Sci. 96: 6791-6796.

Shiratori, H., Sakuma, R., Watanabe, M., Hashiguchi, H., Mochida, K., Sakai, Y., Nishino, J., Saijoh, Y., Whitman, M., and Hamada, H. 2001. Two-step regulation of left-right asymmetric expression of Pitx2: Initiation by nodal signaling and maintenance by Nkx2. Mol. Cell 7: 137-149.

Sibilia, M., Wagner, B., Hoebertz, A., Elliott, C., Marino, S., Jochum, W., and Wagner, E.F. 2003. Mice humanised for the EGF receptor display hypomorphic phenotypes in skin, bone and heart. Development 130: 4515-4525.

Siegel, P.M. and Massagué, J. 2003. Cytostatic and apoptotic actions of TGF- $\beta$ in homeostasis and cancer. Nat. Rev. Cancer 3: $807-821$.

Song, J., Oh, S.P., Schrewe, H., Nomura, M., Lei, H., Okano, M., Gridley, T., and Li, E. 1999. The Type II Activin receptors are essential for egg cylinder growth, gastrulation, and rostral head development in mice. Dev. Biol. 213: 157-169.

Takenoshita, S., Mogi, A., Nagashima, M., Yang, K., Yagi, K., Hanyu, A., Nagamachi, Y., Miyazono, K., and Hagiwara, K. 1998. Characterization of the MADH2/Smad2 gene, a human Mad homolog responsible for the transforming growth factor- $\beta$ and activin signal transduction pathway. Genomics 48: $1-11$.

Tremblay, K.D., Hoodless, P.A., Bikoff, E.K., and Robertson, E.J. 2000. Formation of the definitive endoderm in mouse is a Smad2-dependent process. Development 127: 3079-3090.

Tsukazaki, T., Chiang, T.A., Davison, A.F., Attisano, L., and Wrana, J.L. 1998. SARA, a FYVE domain protein that recruits Smad2 to the TGF $\beta$ receptor. Cell 95: 779-791.

Varlet, I., Collignon, J., and Robertson, E.J. 1997. Nodal expression in the primitive endoderm is required for specification of the anterior axis during mouse gastrulation. Development 124: 1033-1044.

Venter, J., Adams, M.D., Myers, E.W., Li, P.W., Mural, R.J., Sutton, G.G., Smith, H.O., Yandell, M., Evans, C.A., Holt, R.A., et al. 2001. The sequence of the human genome. Science 291: 1304-1351.

Vincent, S.D., Dunn, N.R., Hayashi, S., Norris, D.P., and Rob- ertson, E.J. 2003. Cell fate decisions within the mouse organizer are governed by graded Nodal signals. Genes \& Dev. 17: 1646-1662.

Waldrip, W.R., Bikoff, E.K., Hoodless, P.A., Wrana, J.L., and Robertson, E.J. 1998. Smad2 signaling in extraembryonic tissues determines anterior-posterior polarity of the early mouse embryo. Cell 92: 797-808.

Wall, N.A., Craig, E.J., Labosky, P.A., and Kessler, D.S. 2000. Mesendoderm induction and reversal of left-right pattern by mouse Gdf1, a Vg1-related gene. Dev. Biol. 227: 495-509.

Whitman, M. 1998. Smads and early developmental signaling by the TGF $\beta$ superfamily. Genes \& Dev. 12: 2445-2462.

$\mathrm{Xu}, \mathrm{L}$. and Massagué, J. 2004. Nucleocytoplasmic shuttling of signal transducers. Nat. Rev. Mol. Cell. Biol. 5: 209-219.

Yagi, K., Goto, D., Hamamoto, T., Takenoshita, S., Kato, M., and Miyazono, K. 1999. Alternatively spliced variant of Smad2 lacking exon 3. Comparison with wild-type Smad2 and Smad3. J. Biol. Chem. 274: 703-709.

Yang, X., Letterio, J.J., Lechleider, R.J., Chen, L., Hayman, R., Gu, H., Roberts, A.B., and Deng, C. 1999. Targeted disruption of SMAD3 results in impaired mucosal immunity and diminished $\mathrm{T}$ cell responsiveness to TGF- $\beta$. EMBO $/$. 18: 1280-1291.

Yang, X., Chen, L., Xu, X., Li, C., Huang, C., and Deng, C.X. 2001 . TGF- $\beta / S \operatorname{mad} 3$ signals repress chondrocyte hypertrophic differentiation and are required for maintaining articular cartilage. J. Cell Biol. 153: 35-46.

Yang, Y.C., Piek, E., Zavadil, J., Liang, D., Xie, D., Heyer, J., Pavlidis, P., Kucherlapati, R., Roberts, A.B., and Bottinger, E.P. 2003. Hierarchical model of gene regulation by transforming growth factor $\beta$. Proc. Natl. Acad. Sci. 100: 1026910274.

Yu, J.K., Holland, L.Z., and Holland, N.D. 2002. An amphioxus nodal gene (AmphiNodal) with early symmetrical expression in the organizer and mesoderm and later asymmetrical expression associated with left-right axis formation. Evol. Dev. 4: 418-425.

Zhu, Y., Richardson, J.A., Parada, L.F., and Graff, J.M. 1998. Smad3 mutant mice develop metastatic colorectal cancer. Cell 94: 703-714. 


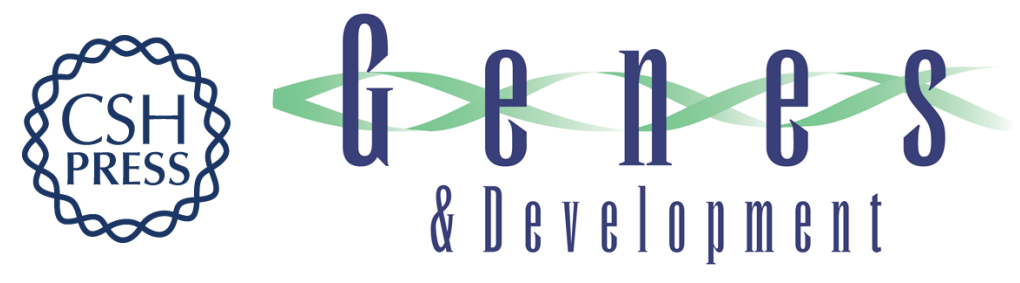

\section{Mice exclusively expressing the short isoform of Smad2 develop normally and are viable and fertile}

N. Ray Dunn, Chad H. Koonce, Dorian C. Anderson, et al.

Genes Dev. 2005, 19:

Access the most recent version at doi:10.1101/gad.1243205

References This article cites 70 articles, 29 of which can be accessed free at: http://genesdev.cshlp.org/content/19/1/152.full.htmI\#ref-list-1

License

Email Alerting

Receive free email alerts when new articles cite this article - sign up in the box at the top Service right corner of the article or click here.

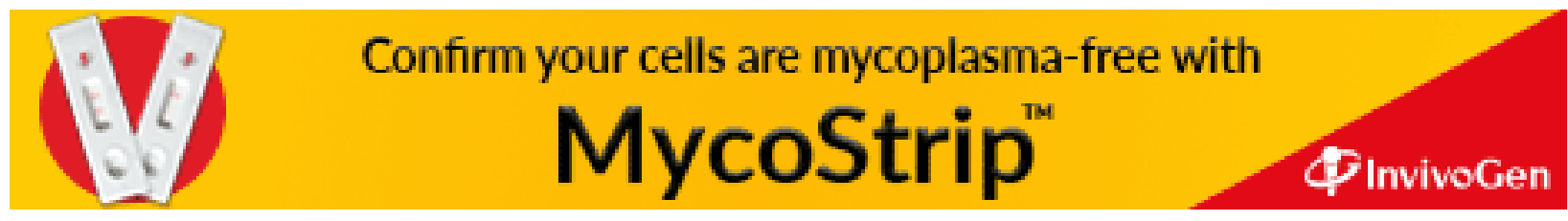

